\title{
Le médecin
}

du prince

Voyage

à travers les cultures

\section{Anne-Marie Moulin}

Simone Gilgenkrantz

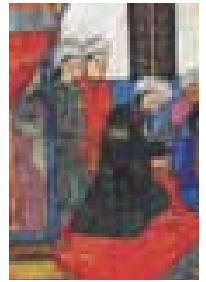

S. Gilgenkrantz:

9 , rue Basse,

54330 Clérey-sur-Brénon, France.

simsimone.gilgenkrantz@gmail.com

C'est au cours d'un voyage à travers les cultures, à travers l'espace et le temps, qu'Anne-Marie Moulin convoque, non pas le médecin, mais les médecins des princes [1].

Comme dans les horloges de Berne ou de Prague où s'animent des personnages, ils surgissent, à l'heure dite, le temps d'évoquer les fastes d'une cour, les recettes de leurs électuaires, ou les composés (un grand nombre: al-Akthar) de leurs élixirs. Et ils nous laissent sur notre faim de les mieux connaître, d'en savoir plus sur eux. Car la plupart sont restés discrets, emportant avec eux les secrets des puissants, rois, princes, papes, califes, sultans ou empereurs moghols qu'ils ont soignés.

Qui sont-ils? Des étrangers venus d'ailleurs, Juifs, chrétiens enlevés en Méditerranée par les Barbaresques, jeunes gens razziés dans les Balkans et éduqués à la cour ottomane, ou encore médecins occidentaux, convaincus de la supériorité de leur science. Elle paraît pourtant ambiguë à l'ère coloniale, quand les intentions humanitaires sont mises en avant lors de la pénétration des territoires. Elle devient même dangereuse, quand les grandes puissances entrent en compétition pour s'accaparer le shah, dont la santé empire dans sa résidence provisoire au Mexique.

Durant le XIXe siècle, la science occidentale favorise la naissance de la santé publique et la modernisation des États nations. Ainsi, Antoine Barthélémy Clot, né à Toulouse, se voit confier par le pacha Méhémet Ali l’organisation de l'école de médecine qui inaugure un état égyptien moderne. Ainsi Mustapha Behcet Efendi, né en Turquie, mais formé à Venise et à Vienne, crée la Tibbhane-i-Amiri, l'école royale de médecine sous le sultan Mahmoud II à Constantinople. Médecin du prince, mais parfois aussi médecin des indigents, comme Moïse ben Maïmon, connu sous le nom de Maïmonide qui, le soir, après son service auprès du sultan, recevait la foule variée affluant à sa consultation [1], ou comme Lillias Hamilton, une des rares femmes 
médecins du prince, mais aussi «médecin des mendiants ». À Kaboul, seule Européenne à la cour pendant la période troublée de la répression des Hrazas chiites de 1894 à 1896, elle devient le médecin attitré de l'émir Abdur Rahman. Jusqu'à son retour en Angleterre, elle garde son entière confiance... quoiqu'il lui faille d'abord tester sur elle-même les potions qu'elle lui prescrit.

Car les médecins passaient parfois pour des empoisonneurs, comme dans un conte des Mille et une nuits: le roi et le médecin Doban où le médecin est décapité mais a pris soin auparavant, pour se venger avant de mourir, d'imprégner les pages de son livre d'un poison violent. Quant au tsar Ivan le Terrible, il fait subir au médecin anglais qu'il soupçonne de trahison la torture la plus atroce qui soit : il est écorché vif.

On n'en finirait pas d'évoquer ces personnages fabuleux que l'auteur décrit d'une plume alerte dans un style si clair qu'on en oublie l'érudition. Ce livre est une somme que l'on peut lire d'un trait, ou consulter à petits coups, en retrouvant dans l'index les noms des centaines de médecins du prince qui y sont évoqués. Ils sont souvent si romanesques qu'ils ont inspiré maintes fictions. Qui sont citées et qu'on voudrait à présent lire ou relire.
À la fin du voyage, ayant surtout exploré le Moyen-Orient, avec des incursions en Extrême-Orient et en Amérique latine, Anne-Marie Moulin, historienne médecin et médecin philosophe, nomade humanitaire de surcroît, nous apporte une humilité mâtinée d'un certain optimisme. Elle nous montre combien nos sciences occidentales sont sujettes à des modes, combien, au regard de l'histoire, elles sont relatives, et comme elles vieillissent vite. Elle nous montre aussi que la confrontation n'est pas nécessairement en faveur de l'Occident: le malade fait son choix selon sa culture. II devient peu à peu autonome. Demain peut-être, chacun d'entre nous apprendra - connais-toi toi même - à devenir un patient-roi. $\diamond$

The doctor of the prince - Travels through the cultures

\section{CONFLIT D'INTÉRÊTS}

L'auteur déclare n'avoir aucun conflit d'intérêts concernant les données publiées dans cet article.

\section{RÉFÉRENCE}

1. Moulin AM. Le médecin du prince - Voyage à travers les cultures. Paris : Odile Jacob, $2010: 362 p$

\section{TIRÉS À PART}

S. Gilgenkrantz

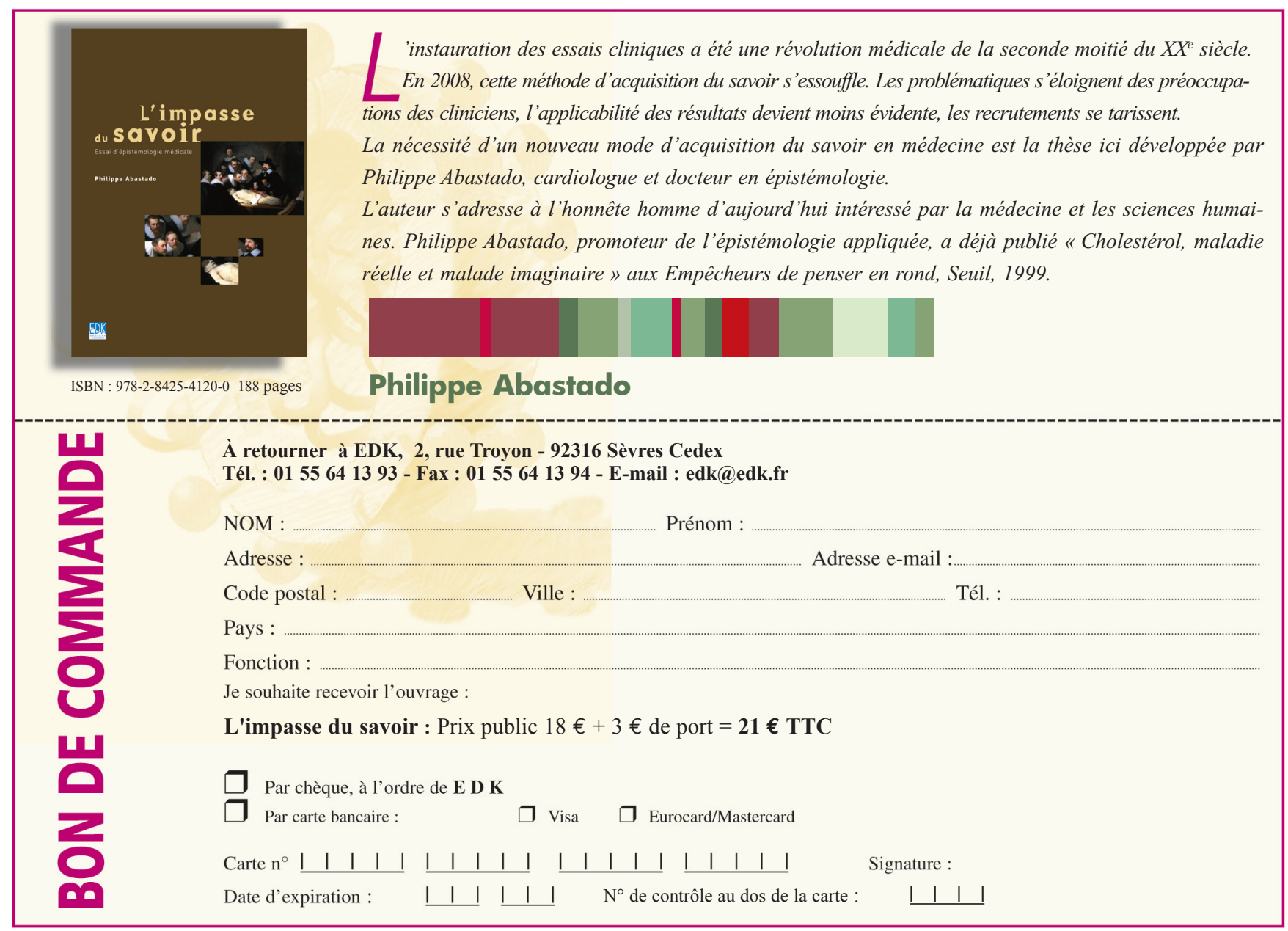

